\title{
CARACTERIZAÇÃO BIOQUÍMICA DE DUAS LINHAGENS DE Candida pseudointermedia ISOLADAS DE BIOMASSA LIGNOCELULÓSICA EM DECOMPOSIÇÃO
}

\author{
E. T. BARRILLI ${ }^{1 *}$, J. R. DEOTI ${ }^{1,3}$, A. A. DOS $\operatorname{SANTOS}^{1,3}$, B. U. STAMBUK ${ }^{3}$, \\ S. L. ALVES JR ${ }^{1}$
}

${ }^{1}$ Engenharia Ambiental e Sanitária, Campus Chapecó, Universidade Federal da Fronteira Sul

${ }^{2}$ Engenharia Ambiental e Sanitária, Campus Erechim, Universidade Federal da Fronteira Sul

${ }^{3}$ Departamento de Bioquímica, Universidade Federal de Santa Catarina

*E-mail para contato: evelyntaize_b@hotmail.com

\begin{abstract}
RESUMO - Como subproduto da produção de etanol a partir da fermentação do caldo de cana-de-açúcar, obtêm-se anualmente cerca de 150 milhões de toneladas de bagaço de cana que podem ser utilizados na produção de etanol 2G. Contudo, a levedura Saccharomyces cerevisiae, embora seja o microrganismo melhor adaptado a processos industriais de fermentação alcoólica, é incapaz de metabolizar significativa parcela dos carboidratos oriundos da hidrólise dessa biomassa, dentre eles a xilose e a celobiose. No intuito de contribuir para a viabilização da produção de etanol $2 \mathrm{G}$, foram analisados os perfis de crescimento celular, consumo de açúcares e produção de etanol de duas linhagens de Candida pseudointermedia isoladas de matéria vegetal em decomposição. Os crescimentos foram realizados em meios mínimos contendo glicose, xilose ou celobiose, com $\mathrm{pH}$ 5,0. Também foram testados meios ajustados em $\mathrm{pH} 3,0$ e $\mathrm{pH}$ 8,0 e outros acrescidos de 5 e $10 \%$ de etanol. Ambas as cepas foram capazes de consumir os três carboidratos disponibilizados, tendo fermentado eficientemente a glicose, e apresentaram tolerância à variação imposta de $\mathrm{pH}$. Por outro lado, as células se mostraram sensíveis a $10 \%$ de etanol, e só foram capazes de crescer em $5 \%$ de etanol após $24 \mathrm{~h}$ de incubação. Os dados obtidos permitem concluir que as linhagens analisadas apresentam potencial para contribuir com a viabilização da produção de etanol $2 \mathrm{G}$, haja vista terem sido capazes de assimilar carboidratos não metabolizados por $S$. cerevisiae.
\end{abstract}

\section{INTRODUÇÃO}

A crescente preocupação com a disponibilidade dos combustíveis fósseis fez a busca por biocombustíveis aumentar, dando maior importância à energia proveniente da biomassa (Goldemberg, 2009). Como subproduto da produção de etanol de primeira geração (a partir da fermentação do caldo de cana-de-açúcar), obtêm-se cerca de 150 milhões de toneladas de bagaço de cana anualmente, algo que pode ser também utilizado na produção de etanol de segunda geração (também conhecido por etanol $2 \mathrm{G}$ ou etanol lignocelulósico), tendo em vista os carboidratos presentes nessa biomassa lignocelulósica. Esse processo tem forte apelo ambiental em virtude de teoricamente permitir o aumento de mais de $50 \%$ na produção de etanol sem aumentar a área de cana plantada (Silva et el., 2014; Soccol et al., 2010). 
O microrganismo mais eficientemente empregado na produção industrial de etanol de primeira geração é a levedura Saccharomyces cerevisiae, que é capaz de fermentar com elevada eficiência a sacarose (Zanin et al., 2000; Stambuk et al., 2008). No entanto, a produção de etanol $2 \mathrm{G}$ requer uma espécie capaz de fermentar os carboidratos xilose e celobiose, encontrados nos hidrolisados lignocelulósicos, uma vez que $S$. cerevisiae não apresenta tal característica (Stambuk et al., 2008; Lee et al., 2013).

Em vista disso, buscou-se caracterizar duas linhagens pertencentes à espécie Candida pseudointermedia (Nakase et al., 1976), previamente isoladas de biomassa vegetal em decomposição. Assim como esses, outros isolados de C. pseudointermedia também já foram encontrados em substratos de matéria vegetal em decomposição, bem como de grãos de café, flores, folhas, insetos, bagaço de cana-de-açúcar e de uma tradicional pasta de peixe no Japão (Barriga et al., 2014). Como ainda existem poucos estudos realizados com esta espécie acerca das suas características metabólicas frente a carboidratos de biomassa lignocelulósica, o presente trabalho testou as linhagens quanto ao consumo de glicose, xilose e celobiose, bem como à tolerância à variação de $\mathrm{pH}$ e a diferentes concentrações de etanol no meio de cultivo. Com isso, objetivou-se contribuir para o aperfeiçoamento da produção de etanol 2G.

\section{MATERIAIS E MÉTODOS}

\subsection{Isolamento e Identificação das Linhagens}

A coleta do material em decomposição ocorreu em dois locais: nas matas dentro dos limites do Campus Chapecó da Universidade Federal da Fronteira Sul (UFFS) e na Unidade de Conservação da Floresta Nacional de Chapecó (FLONA). As leveduras foram isoladas conforme protocolo de Cadete et al. (2009). A identificação das leveduras foi realizada através do sequenciamento da região ITS-5.8S e dos domínios D1/D2 do gene que codifica o rRNA 26S. As sequências foram subsequentemente comparadas àquelas disponíveis no banco de dados GenBank por meio da ferramenta BLAST (em http://www.ncbi.nlm.nih.gov).

\subsection{Crescimento Celular, Consumo de Açúcares e Produção de Etanol}

As células foram inicialmente pré-cultivadas por $48 \mathrm{~h}$ antes de serem inoculadas em frascos Erlenmeyer contendo 1/5 do volume de meio líquido, sendo a cultura incubada em um agitador a $25^{\circ} \mathrm{C}$ e $145 \pm 10 \mathrm{rpm}$. Em tempos pré-determinados, foram retiradas amostras para determinação do crescimento celular por espectrofotometria a $570 \mathrm{~nm}$ (DO570nm). Foram utilizados meios sintéticos mínimos $(0,67 \%$ de base nitrogenada) contendo alternadamente $2 \%$ de glicose, xilose ou celobiose como fontes de carbono, cujo $\mathrm{pH}$ foi ajustado em 5,0. Ainda foram utilizados meios sintéticos mínimos com $2 \%$ de glicose ajustados em pH 3 e pH 8 e outros acrescidos de $5 \%$ e $10 \%$ de etanol.

A dosagem dos açúcares glicose, xilose e celobiose consumidos durante os crescimentos celulares foi realizada através do método de DNS em microplacas desenvolvido por Santos et al. (2017). A partir das alíquotas coletadas durante os crescimentos celulares também foi possível quantificar o etanol através da reação enzimática que utiliza a álcool oxidase (AOD) e a peroxidase (POD), seguindo metodologia adaptada do protocolo descrito por Rodionov et al. (2002). Os rendimentos de etanol foram calculados conforme Schmidell et al. (2001), correlacionando o produto obtido com o substrato consumido $\left(Y_{e / s}\right)$. 


\section{RESULTADOS E DISCUSSÃO}

As duas linhagens testadas de $C$. pseudointermedia foram capazes de crescer em meios contendo, alternadamente, glicose, xilose ou celobiose como fontes de carbono. Com exceção do crescimento da cepa FLONA-CE-3.4 em celobiose, onde não foi observado o consumo completo do açúcar disponível no meio, em todos os outros cultivos, os carboidratos foram esgotados. Nota-se ainda que o consumo total de glicose deu-se após 25 horas, sendo mais veloz que a assimilação dos demais carboidratos, que precisaram de aproximadamente 40 horas para serem consumidos (Figura 1). De fato, recentemente outra pesquisa que utilizou leveduras da mesma espécie, porém coletadas no arquipélago de Galápagos no Equador, indicou que $C$. pseudointermedia é capaz de fermentar a xilose em meio contendo extrato de levedura e peptona como fontes de nitrogênio (Guamán-Burneo et al., 2015).

Figura 1 - Perfis de crescimento celular (A, C, E) e consumo de açúcares (B, D, F) das linhagens UFFS-CE-3.6 (•) e FLONA-CE-3.4 (^), em meios contendo $2 \%$ de glicose (A, B), xilose $(\mathrm{C}, \mathrm{D})$ ou celobiose $(\mathrm{E}, \mathrm{F})$.

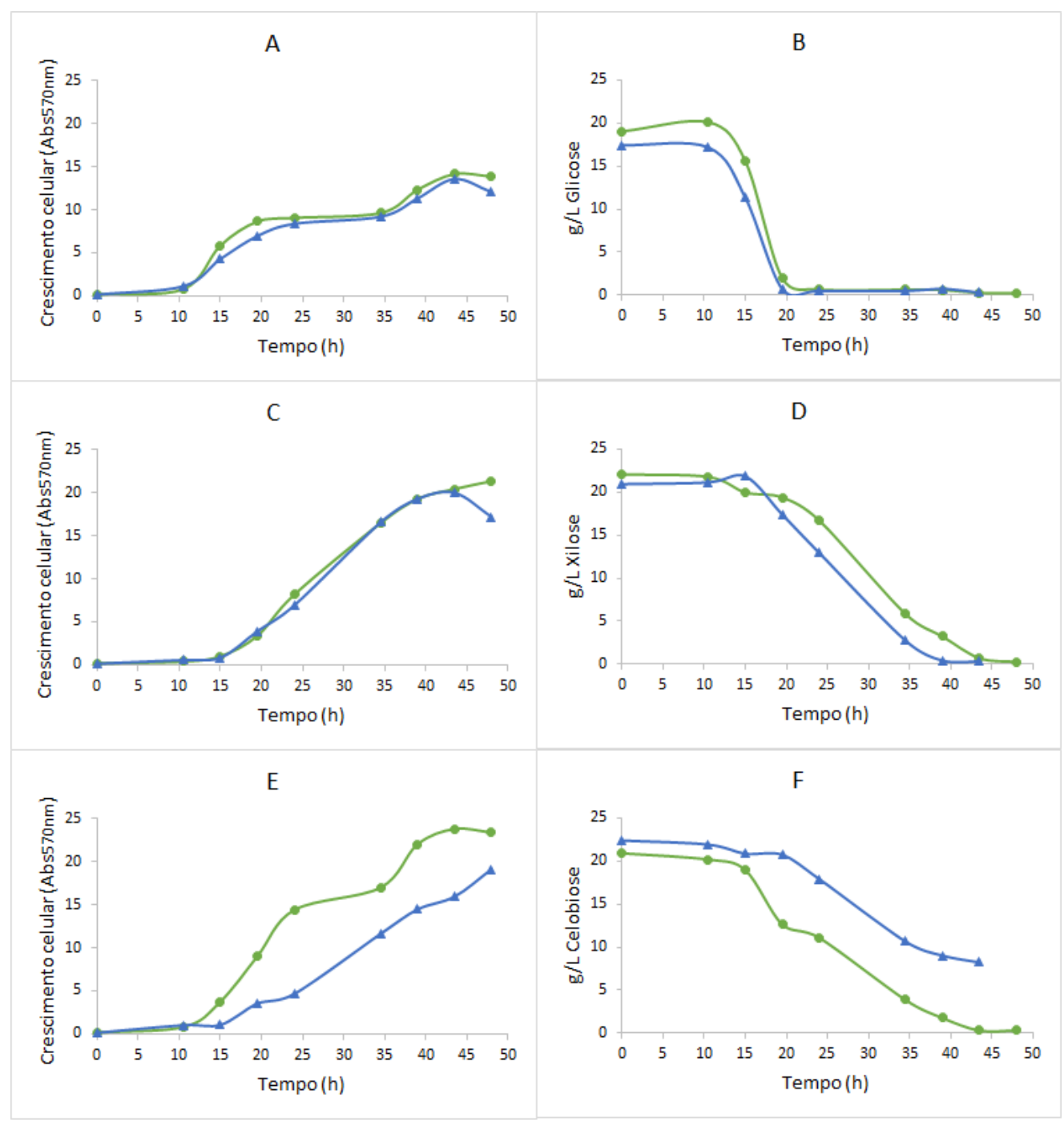


Tendo em vista que durante a fermentação nas usinas as leveduras estão sujeitas a ambientes mais ácidos, as linhagens UFFS-CE-3.6 e FLONA-CE-3.4 também foram avaliadas em meios com diferentes valores de $\mathrm{pH}$. Conforme pode ser verificado na Figura 2, a variação do $\mathrm{pH}$ dos meios para 3,0 e 8,0 não influenciou o crecimento celular em glicose, sendo que os perfis de crescimento apresentaram-se semelhantes aos meios cujo pH estava ajustado para 5,0 (Figura 1A). Da mesma forma, a fase final do processo fermentativo impõe às células altas concentrações de etanol, de modo a ser altamente desejável que as leveduras empregadas apresentem tolerância a esse álcool (Ruyters et al., 2015). Portanto, as cepas UFFS-CE-3.6 e FLONA-CE-3.4 foram ainda testadas quanto à sua sensibilidade ao etanol. Essas linhagens, entretanto, não toleraram $10 \%$ de etanol no meio, e só foram capazes de crescer em 5\% de etanol após uma fase lag de 24 h (Figura 3).

Figura 2 - Perfis de crescimento celular das linhagens UFFS-CE-3.6 (•) e FLONA-CE-3.4 $(\triangle)$, em meios contendo $2 \%$ de glicose com pH 3,0 (A) ou pH 8,0 (B).

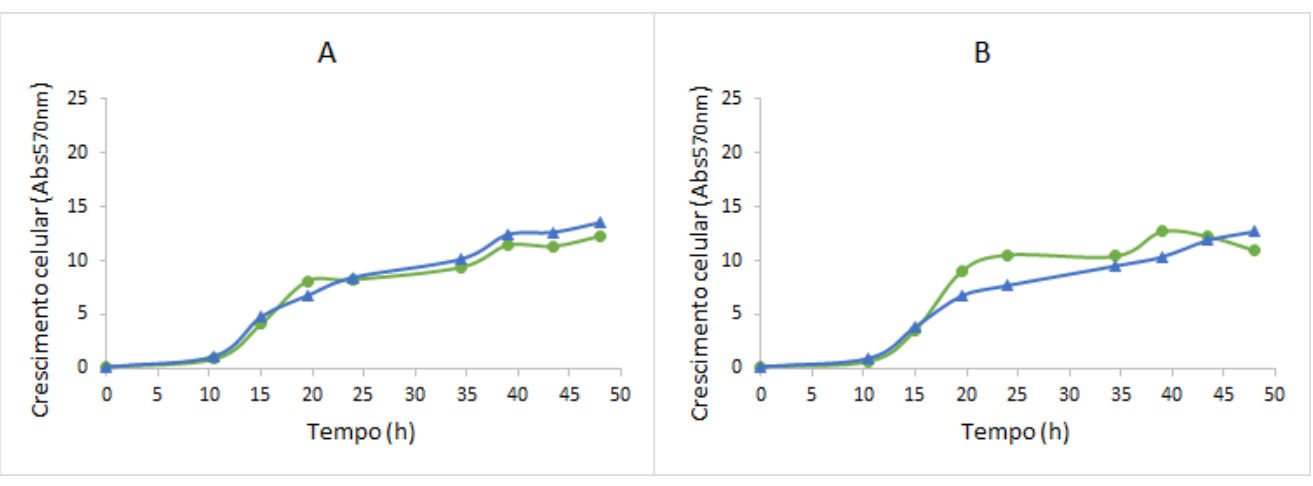

Figura 3 - Perfis de crescimento celular das linhagens UFFS-CE-3.6 (•) e FLONA-CE-3.4 (A), em meios contendo $2 \%$ de glicose acrescidos de $5 \%$ (A) ou 10\% de etanol (B) em pH 5,0.

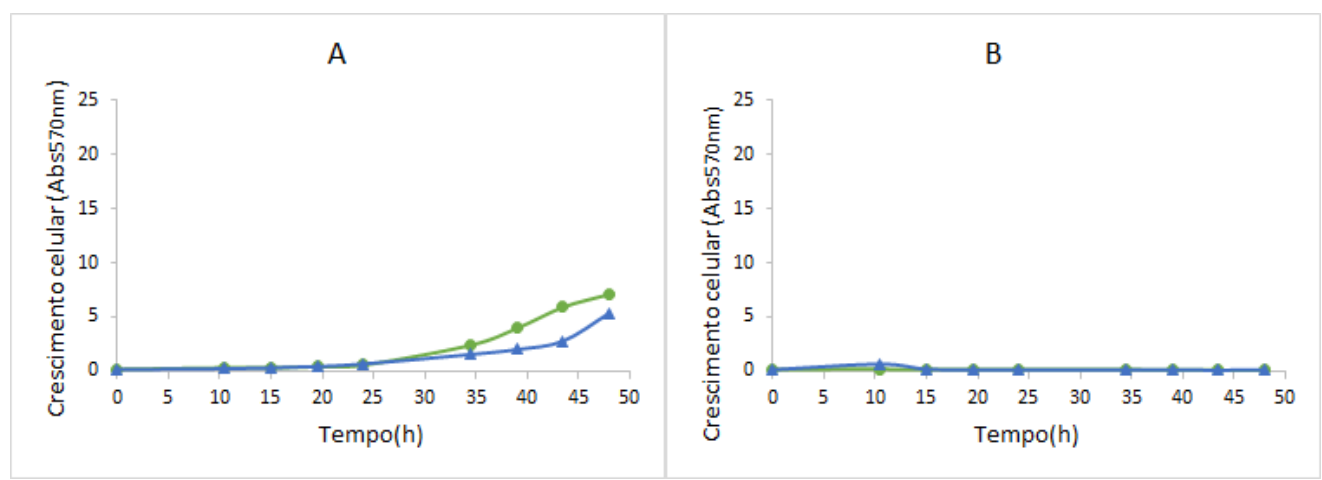

Ao longo dos crescimentos celulares, também foi avaliada a produção de etanol pelas células (dados não mostrados). Embora as leveduras tenham metabolizado a xilose e a celobiose por meio da respiração celular (portanto, sem produção de etanol), ambas 
fermentaram a glicose, tendo a cepa UFFS-CE-3.6 produzido 4,52 g/L de etanol e a FLONACE-3.4, 6,08 g/L. Tomando por base a quantidade de glicose por elas consumida, isso corresponde a um rendimento de etanol $\left(Y_{e / s}\right)$ de 0,23 e $0,30 \mathrm{~g} / \mathrm{g}$ respectivamente. Considerando o fato de os cultivos terem sido realizados em aerobiose plena e com amônia como fonte de nitrogênio, considera-se satisfatório esses rendimentos, que correspondem a $45 \%$ e $59 \%$ do rendimento máximo teórico $(0,51 \mathrm{~g} / \mathrm{g})$. Hande et al. (2013) demonstraram que, quando amônia é a fonte de nitrogênio, o rendimento de etanol pode cair a quase metade daquele observado em meios cuja fonte de nitrogênio provém de extrato de levedura e casaminoácidos. É possível que essa diferença da fonte de nitrogênio explique até mesmo a preferência das células em respirarem, em vez de fermentarem, a xilose e a celobiose. Desse modo, seriam interessantes novos trabalhos para avaliar o rendimento fermentativo dessas leveduras em meios com diferentes fontes de nitrogênio.

\section{CONCLUSÃO}

Embora não tenham fermentado a xilose e a celobiose, as duas linhagens de $C$. pseudointermedia testadas foram capazes de assimilar esses dois carboidratos, demonstrando, assim, possuir as enzimas necessárias à metabolização de ambos açúcares. Ademais, essa ausência de fermentação pode ter ocorrido em razão da fonte de nitrogênio utilizada e do cultivo em aerobiose plena. Assim sendo, as duas leveduras apresentam potencial para contribuir com a otimização da produção de etanol $2 \mathrm{G}$ por possuírem os transportadores e as enzimas necessárias ao metabolismo de carboidratos encontrados nos hidrolisados lignocelulósicos. Os genes que codificam essas proteínas podem, portanto, vir a ser heterologamente expressos em células de S. cerevisiae.

\section{AGRADECIMENTOS}

Os autores agradecem à Bióloga Ana Raquel de Oliveira Santos e ao Prof. Dr. Carlos Augusto Rosa, do Depto. de Microbiologia da UFMG, pela identificação das leveduras.

\section{REFERÊNCIAS}

BARRIGA E. J. C.; BARAHONA, P. P.; TUFIÑO, C.; BASTIDAS, B.; GUAMÁNBURNEO, C.; FREITAS, L.; ROSA, C. An Overview of the Yeast Biodiversity in the Galápagos Islands and Other Ecuadorian Regions, Biodiversity - The Dynamic Balance of the Planet, PhD. Oscar Grillo (Ed.), InTech, 2014.

CADETE, R. M.; SANTOS, R. O.; MELO, M. A.; MOURO, A.; GONÇALVES, D. L.; STAMBUK, B. U.; GOMES, F. C. O.; LACHANCE, M. A.; ROSA, C. A. Spathaspora arborariae sp. nov., a D-xylose-fermenting yeast species isolated from rotting wood in Brazil. FEMS Yeast Res., v. 9, p. 1338-1342, 2009.

GOLDEMBERG, J. Biomassa e energia. Quim. Nova, v. 32, p. 582-587, 2009.

GUAMÁN-BURNEO, M. C.; DUSSÁN, K. J.; CADETE, R. M.; CHEAB, M. A.; PORTERO, P.; CARVAJAL-BARRIGA, E. J.; DA SILVA, S. S.; ROSA, C. A. Xylitol production by yeasts isolated from rotting wood in the Galápagos Islands, Ecuador, and 
description of Cyberlindnera galapagoensis f.a., sp. nov. Antonie van Leeuwenhoek, v. 108, p. 919-931, 2015.

HANDE, A.; MAHAJAN, S.; PRABHUNE, A. Evaluation of ethanol production by a new isolate of yeast during fermentation in synthetic medium and sugarcane bagasse hemicellulosic hydrolysate. Ann. Microbiol., v. 63, p 63-70, 2013.

LEE, W. H.; NAN, H.; KIM, H. J.; JIN, Y. S. Simultaneous saccharification and fermentation by engineered Saccharomyces cerevisiae without supplementing extracellular ß-glucosidase. J. Biotechnol., v. 167, p. 316-322, 2013.

NAKASE T., KOMAGATA K., FUKAZAWA Y. Candida pseudointermedia sp. nov. isolated from "Kamaboko", a traditional fish-paste product in Japan. J. Gen. Appl. Microbiol., v. 22, p. 177-182, 1976.

RODIONOV, Y. V.; KEPPEN, O. I.; SUKHACHEVA, M. V. A photometric assay for ethanol. Appl. Biochem. Microbiol., v. 38, p. 395-396, 2002.

RUYTERS, S.; MUKHERJEE, V.; VERSTREPEN, K. J.; THEVELEIN, J. M.; WILLEMS, K. A.; LIEVENS, B. Assessing the potential of wild yeasts for bioethanol production. $J$. Ind. Microbiol. Biotechnol., v. 42, p. 39-48, 2015.

SCHMIDELL, W.; LIMA, U. D. A.; AQUARONE, E.; BORZANI, W. Modelagem matemática e simulação de processos fermentativos. Biotechnol. Ind., v. 2, p. 123-178, 2001.

SANTOS, A. A.; DEOTI, J. R.; MÜLlER, G.; DÁRIO, M. G.; STAMBUK, B. U.; ALVES S. L. Jr. Microwell plate-based method for the determination of reducing sugars with the DNS reagent. Braz. J. Food Technol., v. 20, p. e2015113, 2017.

SILVA, L. F.; TACIRO, M. K.; RAICHER, G.; PICOLLI, R. A.; MENDONÇA, T. T.; LOPES, M. S.; GOMEZ, J. G. Perspectives on the production of polyhydroxyalkanoates in biorefineries associated with the production of sugar and ethanol. Int. J. Biol. Macromol., v. 71, p. 2-7, 2014.

SOCCOL, C. R.; VANDENBERGHE, L. P.; MEDEIROS, A. B.; KARP, S. G.; BUCKERIDGE, M.; RAMOS, L. P.; PITARELO, A. P.; FERREIRA-LEITÃO, V.; GOTTSCHALK, L. M.; FERRARA, M. A.; DA SILVA BOM, E. P.; DE MORAES, L. M.; ARAÚJO, J. A.; TORRES, F. A. Bioethanol from lignocelluloses: Status and perspectives in Brazil. Bioresource Technology, v. 101, p. 4820-4825, 2010.

STAMBUK, B. U.; ELEUTHERIO, E. A.; FLOREZ-PARDO, L. M.; SOUTO-MAIOR, A.; BON, E. S. Brazilian potential for biomass ethanol: challenge of using hexose and pentose cofermenting yeast strains. J. Sci. Ind. Res., v. 67, p. 918-926, 2008.

ZANIN. G. M.; SANTANA C. C.; BOM, E. P.; GIORDANO, R. C.; DE MORAES, F. F.; ANDRIETTA, S. R.; DE CARVALHO NETO, C. C. Brazilian Bioethanol Program. Appl. Biochem. Biotechnol., v. 84-86, p. 1147-1161, 2000. 